\section{Birlesik Dúnya Arastrma Cypriot Journal of Educational \\ BD-CENTER \\ Sciences}

Innovasyon ve Yayınalık Merkezi
Volume 16, Issue 2, (2021) 641-658

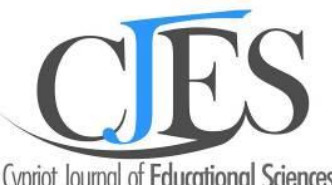

Cypriot Joumal of Educational Sciences

$\underline{\text { www.cjes.eu }}$

\title{
Examining the relation between form information and movement in music education: The skeleton dance
}

Çiğdem Eda Angı *, Niğde Ömer Halisdemir University, Faculty of Education, Department of Music Education, Niğde, Turkey. https://orcid.org/0000-0002-2611-0844

\section{Suggested Citation:}

Angı, Ç. E. (2021). Examining the relation between form information and movement in music education: The skeleton dance. Cypriot Journal of Educational Science. $16 \quad$ (2), $641-658$. https://doi.org/10.18844/cjes.v16i2.5641

Received from January 05, 2021; revised from February 28, 2021; accepted from April 12, 2021.

(C)2021 Birlesik Dunya Yenilik Arastirma ve Yayincilik Merkezi. All rights reserved.

\begin{abstract}
Providing examples suitable for the children's world in the music education given to younger age groups may reinforce the knowledge to be taught. For this reason, cartoons can be utilized for an engaging and fun lesson environment. One of the best examples of this situation is believed to be the short cartoon series Silly Symphony produced by Walt Disney. The most important feature of the cartoon that makes it significant to be used in music education is that the music was composed before the images, i.e., the images were drawn in accordance with the technical and structural characteristics of the music. The aim of the research is to examine the musical characteristics of The Skeleton Dance, the first cartoon of the series, and the relationship between form structure and movement. This is a descriptive research. After the evaluations conducted, it was concluded that the use of cartoon in children's music education in terms of listening, analysis / grouping and application dimensions would be positive and beneficial.
\end{abstract}

Keywords: Music Education, Form Information, Cartoon, Silly Symphony, The Skeleton Dance, Movement.

* ADDRESS FOR CORRESPONDENCE: Niğde Ömer Halisdemir University, Faculty of Education, Department of Music Education, Niğde, Turkey. E-mail address: edaangi@yahoo.com / Tel.: +90-388-225-3014 


\section{Introduction}

Music, which has a unique eloquentness, is one of the most important branches of art. Music, which reserves an indispensable place in the life of people of all age groups starting from birth, has become a common and universal language all over the world, thanks to its universal structure. Gordon (2003) states that although music is a universal language, music without grammar is not a 'linguistic' language and therefore a child learns it just as he/she learns a language.

Home is the most important school children will know; on the other hand, family is the most important teacher children can have. Most families are more competent in developing their children's language and arithmetic skills, providing guidance and information rather than revealing, improving their children's musical talents or enabling them to understand music. Many families are not musically competent because they are not guided or informed about gaining the understanding of music in their childhood. Therefore, families are unwittingly and inevitably entering into a vicious circle of these issues (if they are not reluctant). Just as families do not need to be professional writers, speakers or mathematicians in teaching their children on topics such as how to use numbers effectively and how to communicate, they also do not need to be amateur or professional musicians in developing their own children's musical understanding, revealing their children's musical talents, informing and guiding them. Music is not a special capability talent granted to some chosen people. Each person has at least some potential in understanding music. Families who sing with a correct intonation compared to others move their bodies with flexible and free-flowing movements and enjoy doing this; even if they do not play a musical instrument, they are able to meet the basic needs of information and guidance of their own children about music (Gordon, 2003). In addition to the musical language, another universal area, even if there is a geography, culture or language differences, is dance.

According to Gulbekian, dance, which is a part of cultural history and communication history, is one of the unique and basic forms of communication, thanks to its unique language (cited by Özevin \& Bilen, 2011). 'Dance has, above all, had a ritualistic, religious function for centuries. Worship of gods, act of contrition, prayers for rain, supplications for abundance, etc. were often described through some improvised or traditional dance moves, or dance tunes. Throughout the ancient Greek and Roman periods, dance gradually shed from its ritualistic image and turned into a conscious art' (Karolyi, 2016, p. 114).

Dance is also an issue that concerns all people who feel like dancing rather than being concerned with gender or age. For creative dancing, knowing the basic movements is necessary and sufficient, because only in this way can the movements be linked with each other. Locomotor movements (walking, running, bouncing, leaping, jumping, prancing, triplet, hopping, galloping and sliding) are performed to the front, back and sides. Axial movements (extension and occlusion, bending and straightening, swinging, spin and contortion) are performed by keeping the feet still and the body moving within an axis. The combination of these is known as traditional dance (waltz, polka, Scottish, mazurka, double step) movements (Özkan, 2006).

According to Brewer, the basic element for dance is creativity. Basic motor skills for creative movements and dance are learned at the age of 3-5 and continue to develop throughout one's life. Education of moving according to music, which is the best way for children to evaluate and love music, should be started from the early years of life. In this period, the focus should be on the 'movement process' rather than the generated outcome (cited by Sığırtmaç, 2005). 
Movements without a rhythm or sedentary rhythm are rare. Rhythmic responses against music can be instinctive; these responses can be further developed and progressed through commands and information. When we grasp a musical sound, the rhythm sometimes invites us to participate in the music through movements. Once such a situation happens, we click our fingers, move our feet, shake our head, swing our body and walk and dance in harmony with the music. We respond to music with emotions and movements. Music mobilises aesthetic and kinaesthetic reactions within us. These natural movements can be used for teachers to achieve specific goals (beat, tempo, numbers, thesis, phrase, form etc.) in teaching music (Shenan, 1987).

Research studies conducted on music and movement in music teaching prove the importance of this situation. In the research conducted by Crumpler, it is argued that children who receive movementbased music education can easily comprehend melodic differences. In Joseph's study, it was found that preschool children who studied music harmonising with body movements perceive and analyse the music they hear well. A child, who concentrates his/her attention and learning intensity on musical sounds, creates body movements in line with these sounds. It is necessary to analyse musical phrases in order to ensure that these movements are made in accordance with music and in a healthy way, and that the body is in coordination with music and rhythm (cited by Kılıç, 2012).

However, it is not possible to follow the flow and various stages of a piece unless one knows the structure of the piece well. If the listener cannot distinguish a piece the next time he/she listens to it, cannot find the necessary signs that tell him/her where it is, he/she will be afraid of these themes that he/she is nor familiar with and thus will behave differently to the piece or oppose understanding it. Even if this is a piece that is established in a known or logical way, the listener may see himself in a predicament and the piece may seem cluttered. 'Is it inevitable that a piece of music has a form and structure? Since music inclines to the senses rather than the mind, is a framework necessary for it? Should the idea of structure be allowed to override the idea of music?' (Hodeir, 2016). When it comes to the education of music, the answer to these questions will inevitably be 'yes'. The movements that are made instinctively when the music is first received turn into more conscious movements as you get to know the music better.

According to Aksnes et al., while listening to music or imagining musical sounds, these sounds will establish natural and involuntary connections between bodily movement images. According to Eitan and Granot, the meaning of music is enabled by experiencing music with physical movements, thanks to this connection established between music and emotions (cited by Özmentes, 2009).

The child should actively participate in the learning process in order for 'interpretation' to be performed fully. For this reason, teaching knowledge of form and basic concepts of music through movements is important for the healthy progress of music education. Kılıç $(2012$, p. 11) explains the relationship between children and movement as follows:

Physically feeling the movement in music, that is, 'hearing' music through movement, is a very important matter for musical development. Therefore, teaching of the lesson through musical activities that include both of the musical movement while working with children has a great function in children's learning and in the development of their musical sensitivity. Haines and Gerber (1996, p. 172) state that children need to improve, have an effective listening skill, place emphasis to the music they listen to, perceive what they hear and reflect what they feel and think with their body in order to increase the power of creative expression and interpretation. Thus, they imply that the child has acquired the ability to store the music he / she listens in his/her mind and gain experience of movement. 
Parents and teachers have important tasks so that the child's taste for music could be developed and a successful education is provided. First of all, it should be ensured that the child is interested in and loves music (Sun \& Seyrek, 1993). If the family or the teacher does not realise this important responsibility and does not undertake it, the child will have a limited understanding of music and enjoyment of music, will grow up assuming that life and art are separate worlds and will not discover that art is a life - life is an art. If this responsibility is undertaken by the family or teachers and the child is introduced to many different types of music, the awareness gained will be reflected in his/her life, he/she will be familiar with music and will be able to understand the language of music, like reading a book (Gordon, 2003).

In order to develop children's musical tastes, it may be beneficial to make children systematically and consciously listen to distinctive, instructive, interesting and short-term pieces, as well as to support the 'listening' action with cartoons, which reserves a great place in their world, and diversify the pieces played by this way. Children may be distracted quickly and their time to concentrate on a task may be shortened. For this reason, having children watch didactic cartoons, which skilfully combine 'auditory' with 'visuality' and are short in structure, so as not to distract them, instead of feature-length cartoons, is seen as an element that facilitates achieving the desired goal. It is believed that the most suitable example for the specified characteristics is the Silly Symphony short cartoon series produced by Walt Disney.

\subsection{Silly Symphony}

Walt Disney was ahead of his time in terms of the many entertainment ventures he created. Walt Disney and his studio are marked with distinct honour by producing the first talking cartoon Steamboat Willie, the first feature-length animated film Snow White and the Seven Dwarfs and Fantasia, the first stereophonic musical film that combines animation and classical music (https://insidethemagic.net/2018/01/walt-disneys-silly-symphonies-year-one-1929/).

Steamboat Willie made its debut in 1928, with a technological marvel and profitable commercial success. Steamboat Willie, which is Walt Disney's first animated short film with fully synchronised movements accompanied by melodies, is also the first cartoon to star in one of the most recognisable characters ever to be introduced to the world as 'Mickey Mouse'. No one had ever seen or heard of such a thing before. Despite his popularity and technologically ground-breaking work as an overhasty innovator, Walt wanted to go further with even more effort, and that was just the beginning (https://ohmy.disney.com/insider/2016/05/19/silly-symphonies/).

After the Mickey Mouse series became popular with a great success, Walt Disney stopped by Kansas City on a business trip to New York and visited his colleague and old friend musician Carl Stalling. This is an important visit in the history of animation in terms of the formation of the Silly Symphony series that came into Stalling's mind (Cmrečak, 2018).

In an interview conducted by Milton Gary with Carl Stalling in 1969 (Goldmark \& Taylor, 2002) Carl Stalling said the following: 'Walt came to me to make the debut of a musical series that I had already in my mind. He thought I had illustrated songs on my mind, but I never thought of anything like that. He was very excited when he found out that what I had in mind was the imitation of the rhythmic and humorous moods into the music that they came back to life and dance with dead and inanimate figures such as skeletons, trees, flowers and the like, and other alive and lively figures. I gave him the idea to be used for four seasons and he made a cartoon for each of them. And before I left, I scored each of them. For the name or title of this series, I suggested that there should be a name that would involve 
'symphony', but also overlap with humour, rather than conventional words such as 'music' or 'musical'. I don't know who had offered, but Walt asked me at a meeting that 'Carl, how the Silly Symphony would sound to you?' So, I said 'Perfect'. This is how Silly Symphony started. Of course, as everyone knows, if it weren't for Walt Disney, there would never be Mickey Mouse. Would there ever be a Silly Symphony? Or who would recommend The Skeleton Dance? This situation sometimes makes me think.'

Since Walt Disney and Carl Stalling started working together in Los Angeles in December 1928, they have had different opinions about the music used in Disney cartoons. Wilfred Jackson, one of the studio's former animators, stating that Walt is a person who has no musical background by no means but also does not accept any restrictions on what can be done, recalls that Stalling and Disney were constantly arguing about the adaptation of movement to music or vice versa. While Walt Disney advocated adapting the music to be created to the movements or tailoring the existing stock music to the movement, Stalling advocated the opposite opinion. These two stubborn men, tired of arguing, reached an agreement for the two series: movement would be the dominant one in the Mickey series (it would dominate) and the music would be the dominant in the other short series. In other words, Disney and Stalling agreed to give priority to 'movement' in the Mickey series, while they agreed to prioritise 'music' in the Silly Symphony series as well. Disney agreed to the suggestion for a short cartoon series, allowing Stalling's idea 'to adapt the cartoon according the pre-created music' because such cartoons had never been made before and Disney was at one point influenced by Stalling's rigid and unwavering views on music (Watts, 1997; Barrier, 2007; Cmrečak, 2018).

The Silly Symphony series is more than just synchronising music and movements. This series, seen as a ground for trying new things from the beginning, is also the first colour cartoon, the first realistic human form and the first cartoons to use a multi-camera system. The Silly Symphony, which is very popular with the audience, has inspired other companies as well: MGM: Happy Harmonies; Paramount: Screen Songs; and Warner Bros: Merry Melodies. This ground-breaking series in the animation industry consists of 75 short cartoons made between 1929 and 1939 (https://www.bcdb.com/cartoons/Walt_Disney_Studios/Shorts/Silly_Symphonies/):

(*OSCAR - Academy Award for Best Animated Short Film)

Table 1. 1929-1932

\begin{tabular}{|c|c|c|c|}
\hline 1929 & 1930 & 1931 & 1932 \\
\hline 1. The Skeleton Dance & 6. Summer & 16. Birds of a Feather & 26. The Bird Store \\
\hline 2. El Terrible Toreador & 7. Autumn & 17. Mother Goose Melodies & 27. The Bears and Bees \\
\hline 3. Springtime & 8. Cannibal Capers & 18. The China Plate & 28. Just Dogs \\
\hline 4. Hell's Bells & 9. Frolicking Fish & 19. The Busy Beavers & 29. Flowers and Trees * \\
\hline \multirow[t]{6}{*}{ 5. The Merry Dwarfs } & 10. Arctic Antics & 20. The Cat's Out & 30. King Neptune \\
\hline & 11. Midnight in a Toy Shop & 21. Egyptian Melodies & 31. Bugs in Love \\
\hline & 12. Night & 22. The Clock Store & 32. Babes in The Woods \\
\hline & 13. Monkey Melodies & 23. The Spider and The Fly & 33. Santa's Workshop \\
\hline & 14. Winter & 24. The Fox Hunt & \\
\hline & 15. Playful Pan & 25. The Ugly Duckling & \\
\hline
\end{tabular}


Table 2. 1933-1935

\begin{tabular}{lll}
\hline \multicolumn{1}{c}{1933} & \multicolumn{1}{c}{1934} & \multicolumn{1}{c}{1935} \\
\hline 34. Birds in The Spring & 41. The China Shop & 49. The Tortoise and The Hare * \\
35. Father Noah's Ark & 42. The Grasshopper and The Ants & 50. The Golden Touch \\
36. Three Little Pigs * & 43. Funny Little Bunnies & 51. The Robber Kitten \\
37. Old King Cole & 44. The Big Bad Wolf & 52. Water Babies \\
38. Lullaby Land & 45. The Wise Little Hen & 53. The Cookie Carnival \\
39. The Pied Piper & 46. The Flying Mouse & 54. Who Killed Cock Robin? \\
40. The Night Before & 47. Peculiar Penguins & 55. Music Land \\
Christmas & 48. The Goddess of Spring & 56. Three Orphan Kittens * \\
& & 57. Cock O’The Walk \\
\end{tabular}

Table 3. 1936-1939

\begin{tabular}{llll}
\hline \multicolumn{1}{c}{1936} & \multicolumn{1}{c}{1937} & \multicolumn{1}{c}{1938} & \multicolumn{1}{c}{1939} \\
\hline 59. Elmer Elephant & 66. Woodland Café & 69. Moth and The Flame & 74. The Practical Pig \\
60. Three Little Wolves & 67. Little Hiawatha & 70. Wynken Blynken and Nod & 75. The Ugly Duckling * \\
61. Toby Tortoise Returns & 68. The Old Mill* & 71. Farmyard Symphony & \\
62. Three Blind Musketeers & & 72. Merbabies \\
63. The Country Cousin * & & 73. Mother Goose Hollywood \\
64. Mother Pluto & & \\
65. More Kittens & & & \\
\hline
\end{tabular}

The Silly Symphony short cartoon series, which is seen as the successor of Fantasia and its subsequent cartoons, won a total of seven Oscar awards in harmony with Tom and Jerry cartoon (https://tvtropes.org/pmwiki/pmwiki.php/WesternAnimation/SillySymphonies).

The Silly Symphony, featuring originally crafted storytelling approaches with distinct changes in artistry and technical prowess that progressed every year, was welcomed less enthusiastically as Walt Disney's focus began to shift to feature films, and ended in April 1939 at the end of 10 years. As the centre of the studio transformed into feature animated films, the mastery, art, ingeniousness, technological advances and experiences finalised in the produced Silly Symphony cartoons became a 'classic' for Disney Animation Studios in a short while (https://insidethemagic.net/2018/08/silly-symphonycartoons-part-10-1939-the-final-chapter/, https://ohmy.disney.com/insider/2016/05/19/silly-symphonies/).

It is believed that the Silly Symphony short cartoon series, which hosts the pioneering works of classical music and jazz music, offers the audience a visual and auditory feast and the composition of the music before the image - drawing the images according to the music, enhances the use of the cartoons in the Silly Symphony series for music education purposes. In order to reveal this situation, it would be appropriate to examine The Skeleton Dance which is both the research subject and the first cartoon of the series. 


\subsection{The Skeleton Dance}

The Skeleton Dance, the first short cartoon in the 'Silly Symphony' series of Disney's short cartoon series, ranks 18th in Jerry Beck's book of the 50 Greatest Cartoons. The Skeleton Dance, which is one of the first examples of the spooky genre, is unique and catchy and also it reserves a significant place among the oldest cartoons, although it is not the first cartoon in terms of being completely musically themed without any dialogue and synchronising movement and music (https://allthetropes.org/wiki/The_Skeleton_Dance).

The Skeleton Dance is Disney's first short film without main characters and with elaborated jokes. The characters in the cartoon consist of nocturnal animals and two pairs of skeletons that are the main source of jokes. There are differences between society at the time of The Skeleton Dance, which emerged in 1929, and society of present day. Today, the vast majority of people who are used to seeing violence, harming, bloodshed, hitting and sexual content on screens will not find The Skeleton Dance uncomfortable, shocking or confusing, unlike the 1920s (Cmrečak, 2018).

Disney said that they had considerable difficulties to show The Skeleton Dance in theatres during 1956, and even the manager of a movie theatre found the cartoon 'very scary (eerie)' and complained on this matter. Although many movie theatres refused to show The Skeleton Dance in its early days (it was banned in Denmark for being terrifying), it soon paved the way for the future triumphant and wellloved short cartoons of the series and made itself accepted today (Barrier, 2007; https://allthetropes.org/wiki/The_Skeleton_Dance).

The Skeleton Dance is a true masterpiece that can tread a fine line between sense of humour and being spooky. Ub Iwerks almost plays with the styles of horror with his drawings of howling dogs, flying bats, owls, black cats fighting on the tombstones of a cemetery etc. The graphics of this cartoon, the style between simplicity and realism used by Iwerks and the background coloured with suggestive shades of grey bring the audience into a nice atmosphere by definitely throwing a notch on the top. Carl Stalling, who made the soundtrack of the cartoon, succeeded in blending his own music with March of the Trolls by E. Grieg, a classical music piece by perfectly mixing them. Also, The Skeleton Dance is the first cartoon to use a live orchestra for its music (http://www.ilsollazzo.com/c/disney/scheda/TheSkeletonDance).

Carl Stalling's answer to the questions Mike Barrier asked about The Skeleton Dance during an interview was as follows: 'The Skeleton Dance takes me back to my childhood. When I was about eight or ten years old, I saw a dancing skeleton ad in The American Boy magazine and asked my dad to give me a quarter, so I could buy the magazine. The skeleton, made of cardboard and attached with a rope under its arms, could be pulled apart, and the skeleton could dance when you pulled the ropes suddenly' ... 'And I suggested The Skeleton Dance as the first subject for the Silly Symphony because since I was a kid, I had always wanted to see skeletons dance and I always liked the skeletons dancing as farcical comedy. I think we all loved the scary or weird drawings or stories, including the kids' (Goldmark \& Taylor, 2002).

The animals in The Skeleton Dance cartoon were drawn in the same way as in the Steamboat Willie cartoon. For instance, when animals produce sounds, parts of their bodies expand due to sound production. When the dog howls in the moonlight, its body widens and its neck grows longer. The same principle applies to other animals as well. It can be concluded that Walt Disney applied the principles of successful animation used in its old projects to the new projects. In light of this logic, another remarkable example in The Skeleton Dance cartoon is the skeletons looking at the screen and the skeletons jumping 
towards the screen which makes the viewer enter into eerie emotions in front of the screen (Cmrečak, 2018).

The cartoon depicts four skeletons having fun and dancing during the night in a deserted graveyard. Figures such as the owl's crowing in fear, the howl of the dog, the flying of the bats, the movement of the tree branches, the spider's crawling, the two cats spitting and yelling on each other over the tombstones and the first skeleton emerging and trying to get a bite from the audience admirably complement the spooky burial atmosphere. The cartoon is also designed with a comedy aspect, as well as its perfectionist humorous and spooky line. Hearing the sound of a rooster, reminding the arrival of the morning and the sunrise, the skeletons panic in order to reach their graves. The skeletons collide with each other because of this panic hurry and fuse together in a different form (a creature with 4 heads and 12 legs) and they make their way home (https://hilaritybydefault.com/2016/12/06/defaultdisney-skeleton-dance-1929/).

\subsection{Problem Status}

Movement is more than an educational and instructive technique used in music classes. The development of musical culture-musical literacy is based on the formation of expression and the experience of all musical skills. Movement is considered to be a major component - a fundamental part, which inherently embodies a pedagogical process, as in the methods, practices or approaches of the 'Comprehensive Musicianship' (CM) advocated by Dalcroze, Kodaly, Orff-Schulwerk and 'Music Learning Theory' (MLT) advocated by Edwin Gordon. These techniques and approaches in music teaching have enforced the acceptance of value and worth of body movements and their existence both musically and in terms of contributing to growth and development in general (Woods, 1987).

There are many styles and various movement activities available to today's music educators. OrffSchulwerk emphasises free exploration and improvisation; Kodaly's method focuses on movement with song materials, emphasising authentic folk dances and singing plays. Dalcroze Eurhythmics aims to teach the basic elements of music through body movements that are usually guided and structured through improvisations performed on the piano. Gordon's MLT allows children 0-6 years old to move freely without rules to the music they are listening to (live or recorded), introducing various movements to musical concepts in a formal way from the age of 6 . CM actively uses movement in music lessons to analyse dances and plays in various cultures, to create choreography, to display performance and to interpret. Although each of these approaches or methods emphasises movement activities from different angles, 'movement' constitutes the basis and central point of their pedagogical processes. In each of these approaches, 'movement' is considered as a tool through which the student can express their feelings and thoughts, form their musical tastes and understand the inner structure of music (Woods, 1987).

The first demonstration of movements regarding the concepts taught by a role model or supporting them with visuals in music lessons, which is a performance-oriented training, may cause the subject to be understood and discussed correctly. It can be argued that the materials to be used in the lesson should be enriched - diversified, the teacher should find / demonstrate / implement understandable, interesting examples that are appropriate for the children's age, inspiring enthusiasm in them and ensuring that they actively participate in this process with instructive examples that are not alien to their own world so that the musical education is progressed in a healthier manner and children can learn by having fun. It is believed that the Silly Symphony short cartoon series should be utilised as an example in the musical education given to children, in order to be able to both hear information about music education with 'audibility' and see 'visually' and to be implemented with 'movements'. 
'The main potential of the cartoons, which is an audio-visual communication tool, focuses on clarifying complexity, visualising the invisible, and enabling immediate and concise teaching' (Can, 1995, p. 73). In this way, it can be ensured that information on the basic concepts of music can be taught or reinforced after being taught in the musical education given to children. According to Morgül (2001), the basic concepts of music can be listed as follows:

- Rhythm, Tempo, Beat

- Sound Dynamics

(f, p, crescendo, decrescendo)

\section{- Melodic Properties of Sound}

(Steepness of the sound, length of the sound, rising descending rank, flat sound-vibrating sound)

\section{- Tonal Properties of Sound}

(Sound sources: vocal-body-instrument, tone generation, sound source creation, instrument groups and music genres)

- Structure Concepts

(Motif, sentence, period, canon, rondo, accompaniment)

\section{- Pattern Concepts}

(Monophonic, polyphonic, homophonic)

In order for these abstract concepts to be perceived, they need to be felt in the body and visualised by picture or drawing. Kodaly recommends dance as the best way to teach the musical phrases. Movement that continues throughout a phrase leaves its place to another movement in the second phrase. When the phrase changes the movement changes as well (Morgül, 2001).

In light of this information, the objective of this research is to determine the availability of The Skeleton Dance cartoon, which is the first cartoon of the Silly Symphony cartoon series, in terms of music education. In order to achieve this goal,

- basic musical characteristics of the cartoon will be determined;

- at the same time, the relationship between the form structure of the cartoon and the movements used will be examined.

\section{Method}

This is a descriptive research. In addition to the literature review method, the document analysis technique was also used. According to Corbin and Strauss, document analysis, which is a systematic method, is used to examine and evaluate all documents, including printed and electronic materials. Document analysis, as in other methods used in qualitative research, involves the examination and interpretation of data in order to extrapolate and create an understanding on the relevant subject (cited by Kıral, 2020).

The dictation and form analysis of the music used in The Skeleton Dance cartoon subject to the study were performed by the researcher. The movements and their durations in the cartoon were also determined chronologically. 


\section{Findings}

It can be said that the cartoon consists of three parts. The first part is $(0.27$ ' -2.37 ') the 'beginning', where the environment is seen and the characters begin to be recognised; the second part is (2.38'3.44 ') the 'development', where four skeletons dance together; and the third and last part is (3.45'5.24 ') the 'ending', where the dose/intensity of the entertainments of the skeletons increases and they return to their graves at sunrise.

\subsection{General musical characteristics}

The measure number of the first part is $4 / 4$; the measure number of the second part is $c$ barre; and the measure number of the third part where Grieg's March of the Trolls is used is determined as 2/4. Metronome beat of the first part is determined as $\int$ : 90. Unit beats struck in the first part are heard as striking the semibrevis in the second part, due to the fact that it is C barre. In the third part, the metronome beat varies between $d: 115-120$. Unit beat is clearly perceived from the first part to the third part. There is a latency time that does not depend on the unit beat when moving from the second part to the 'ending' part. In the third part, it is seen that the pace accelerates with the appearance of the rooster that reminds them of the sunrise and the skeletons flee anxiously.

There are various examples from cartoons about note and rest duration values. Some examples from the first part can be listed as follows: owl crowing at the time value of semibrevis $\left(0.37^{\prime}-0.40^{\prime}, 0.46^{\prime}-\right.$ $0.48^{\prime}, 2.06^{\prime}-2.08^{\prime}$ and $\left.2.14^{\prime}-2.16^{\prime}\right)$, advancement of the minute hand in church clock with quarter note $\left(0.48^{\prime}-0.50^{\prime}\right)$, the church bell ringing at the time value of semibrevis $\left(0.51^{\prime}-1.01^{\prime}\right)$, bats flapping their wings with quarter note $\left(0.37^{\prime}-0.40^{\prime}\right)$, dog howling for six beats and rest value for two beats $\left(1.02^{\prime}-\right.$ 1.07').

When we look at the melodic characteristics of the sound in the cartoon, it is possible to see the examples of the ascending-descending scale and chromatic scale $\left(1.31^{\prime}-1.37^{\prime}\right)$ in the scene of the appearance of the skeleton rising from the grave and the rising and descending of the furs of the terrified cats; likewise, the howl of the dog can be given as an example to the flat line sound and crowing of the chicken can be an example of wavy sound. There is no significant difference in the cartoon regarding the subject of sound dynamics ( $f, p$, crescendo, decrescendo).

\subsection{Form information and movement}

Determining the number of measures in this section is important in terms of understanding that the images of the cartoon/the movements displayed are drawn in accordance with the music and being as a preliminary section for comprehending the 'form information' which is the subject of research.

Metronome is determined as $: 90$. However, at times, this number tends to descend or ascend with very small values. However, this deceleration or acceleration is not regarded as a situation that disrupts the rhythm. In the first step, it was determined which movements had how many measures by determining the number of measures and unit beats, counting from one to four rhythmically and continuously. In order to make the scene transitions more comprehensible, the scenes were written in groups; the movements performed in the scenes are matched chronologically with measure number and time:

Group 1: Tree scaring the owl is 4 measures $\left(0.27^{\prime}-0.37^{\prime}\right)$, owl's crowing is 1 measure $\left(0.37^{\prime}-0.40^{\prime}\right)$, tree scaring the owl is 2 measures $\left(0.41^{\prime}-0.45^{\prime}\right)$, owl's crowing is 1 measure $\left(0.46^{\prime}-0.48^{\prime}\right)$. 
Group 2: Advancement of the minute hand in the church clock is 1 measure $\left(0.48^{\prime}-0.50^{\prime}\right)$, church bell ringing - bats flying with flapping wings is 4 measures $\left(0.51^{\prime}-1.01^{\prime}\right)$, howling of the dog is 2 measures $(1.02 '-1.07 ')$.

Group 3: The cats meowing angrily at each other is 2 measures $\left(1.07^{\prime}-1.12^{\prime}\right)$, the cat on the right pulling and releasing the whisker of the cat on the left is 2 measures $\left(1.12^{\prime}-1.17^{\prime}\right)$, the cat on the left pulling and releasing the whisker of the cat on the right is 2 measures $\left(1.18^{\prime}-1.22^{\prime}\right)$, the cats spitting at each other is 2 measures $\left(1.22^{\prime}-1.28^{\prime}\right)$, the cats staring and waiting for the skeleton to come out is 1 measure $\left(1.28^{\prime}-1.31^{\prime}\right)$, the skeleton coming out of the grave - cats running away in fear - skeleton looking around - clattering teeth is 5 measures $\left(1.31^{\prime}-1.44^{\prime}\right)$, the skeleton leaping from the grave to the ground is 2 measures $\left(1.45^{\prime}-1.49^{\prime}\right)$.

Group 4: The skeleton's walking first to the right and then to the left is 4 measures $\left(1.50^{\prime}-2.00^{\prime}\right)$, the skeleton's bouncing is 2 measures $\left(2.01^{\prime}-2.05^{\prime}\right)$, the owl's crowing is 1 measure $\left(2.06^{\prime}-2.08^{\prime}\right)$, the skeleton's escaping in fear - hiding behind the grave and searching for the source of the sound is 2 measures $\left(2.09^{\prime}-2.13^{\prime}\right)$, the owl's crowing is 1 measure $\left(2.14^{\prime}-2.16^{\prime}\right)$, angry skeleton's throwing its own head out at the owl - head hitting the owl - owl's losing its feathers is 2 measures $\left(2.17^{\prime}-2.21^{\prime}\right)$, head bouncing back to the skeleton - settling in its former place is 2 measures $\left(2.22^{\prime}-2.26^{\prime}\right)$.

Group 5: Four skeletons showing their heads first one by one and then collectively - rattling their teeth is 2 measures $\left(2.27^{\prime}-2.32^{\prime}\right)$, the skeletons walking-running and coming to the dance floor is 2 measures $\left(2.33^{\prime}-2.37^{\prime}\right)$.

As is seen in the foregoing groups, the movements and music in the cartoon become more 'understandable' for the audience, thanks to hearing the auditory supported by visuality and seeing the visuality supported by auditory. Thanks to the interpretation of structure, the person (audience/instructor/ student) can gradually turn into a conscious audience / listener, as well as gain a new perspective. It will be inevitable that the movements watched or the music listened to become more meaningful to the person by virtue of the awareness gained in the cartoon.

The tone of the piece used in the second part, which is $C$ barre, was determined as $F$ minor, the metronome rate was determined as 180 and its form was a three-part song. There are two phrases in each part: 4 measure questions (half step-premise) and 4 measure answers (full step-posteriori). Melodically, the first and third parts are identical.

$\begin{array}{ccc}A & B & A \\ a+a^{\prime} & b^{\prime}+b^{\prime} & a+a^{\prime}\end{array}$




\section{First Part}

There are two phrases in the first part. The repetitive period using the volta is also supported with visuals and the same movement is provided.

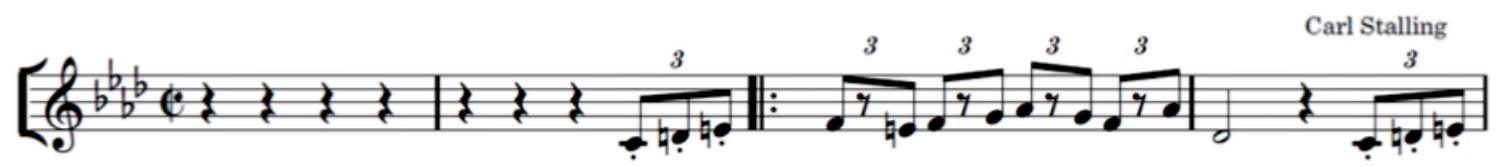

$\left(02.40-02.50^{\prime}\right)$

1. Walking left Jumping on the spot

$\left(02.50^{\prime}-03.02^{\prime}\right)$

2. Walking right Jumping on the spot

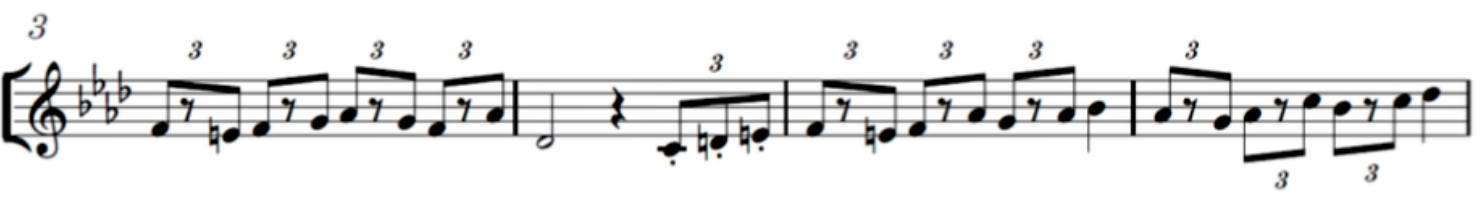

1. Walking left Jumping on the spot Swinging.

2. Walking right Jumping on the spot Swinging

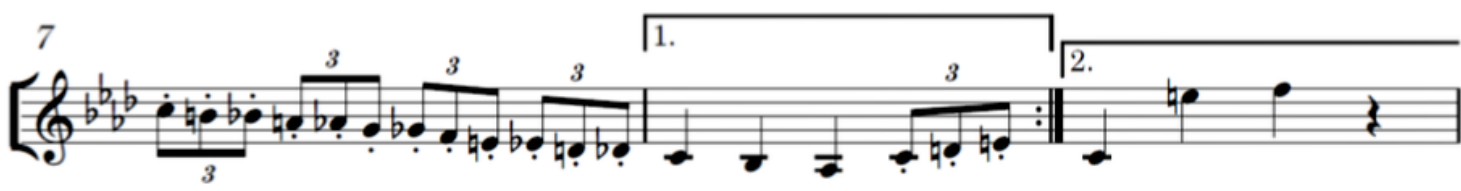

1. Gradually grouching on the ground (left)

1. Standing up one by one

2. Gradually grouching on the ground (left)

2. Getting up all together

Since the period is repeated, in the first volta (8 measures), a movement rank that develops from bottom to top is considered and this thought is drawn as the skeletons standing up one by one in accordance with the unit beat in the cartoon. In the second volta, which creates a completely stable ending effect ( 9 measures), the movement that develops from top to bottom is considered and, in the cartoon, this thought is drawn as skeletons jumping up with the tone (e) and descending in the decision tone (fa).

The skeletons make movements (walking, jumping and swinging) in accordance with the unit beat in all measures except the 7th measure, in which there is a chromatic descending sequence of 12 notes in the first part; on the 7th measure, they descend gradually to the ground in accordance with the chromatic descending sequence characteristics, with a movement to each note.

\section{Second Part}

In the second part, there are two phrases with connections between them, as in the first part. The period was repeated using the volta. However, the difference of this part from the first one is that the movements are changed in a repeated period using the volta. Although there are the same notes in the repeated periods, different movements are drawn. It is believed that the movements are differentiated as it is desired to enrich the visuality in the cartoon and create variety. 


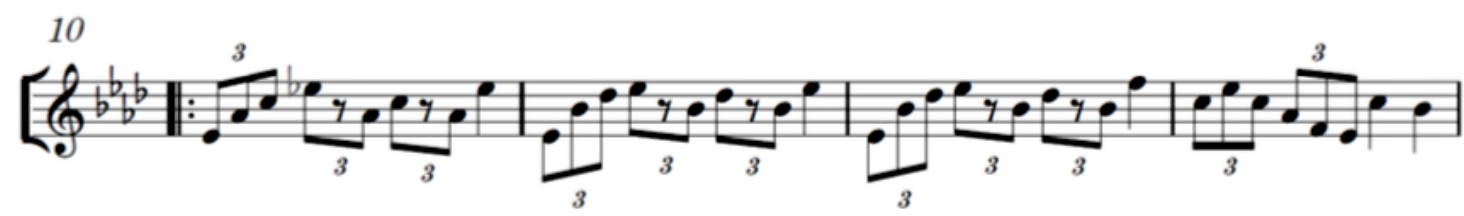

$\left(03.02^{\prime}-03.12^{\prime}\right)$ 1. Turning left hand in hand. Spinning around.

$\left(03.12^{\prime}-03.22^{\prime}\right)$ 2. Length shortening (left), length extending (right)

Change the movement

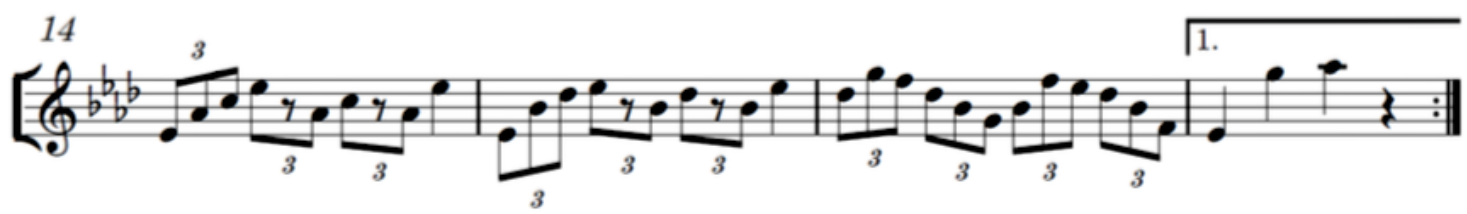

1. Turn right hand in hand. Spinning around 1. Jumping-Positioning

2. Length extending (left), Length shortening (right) Turning back to normal

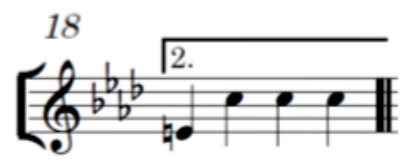

2. Preparing for the jumping movement

Movements in the period of 8 measures were drawn in accordance with 4 measure question phrases and 4 measure answer phrases. The skeletons in the question phrase holding hands in 4 measures, turning to the right and spinning around themselves, make the same movement in the answer phrase of 4 measures in the opposite direction. In the repetition of the period, the number of skeletons dropped to 2 and they are in a different movement pattern. For returning to the main tone in the third part, the second part makes a dominant stable finish.

\section{Third Part}

The third part is the same as the first part, but the movements made in the first part are not used in the third part so that the cartoon does not become monotonous together with the same melody and the same movements, and the children see more visually different movements, and the movement pattern is differentiated. 


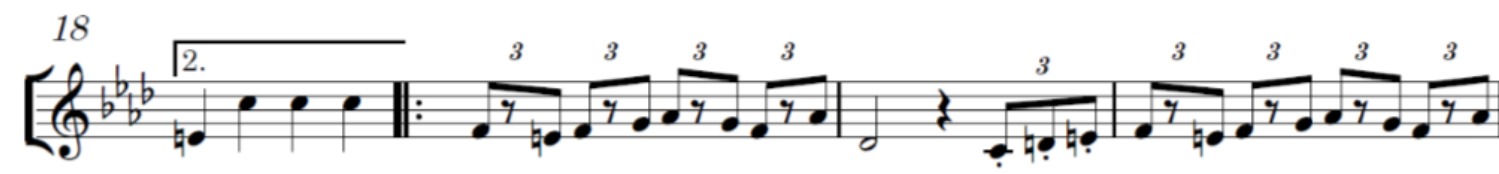

(03.23'-03.33') 1. Jumping left ..

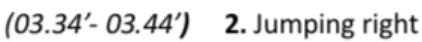

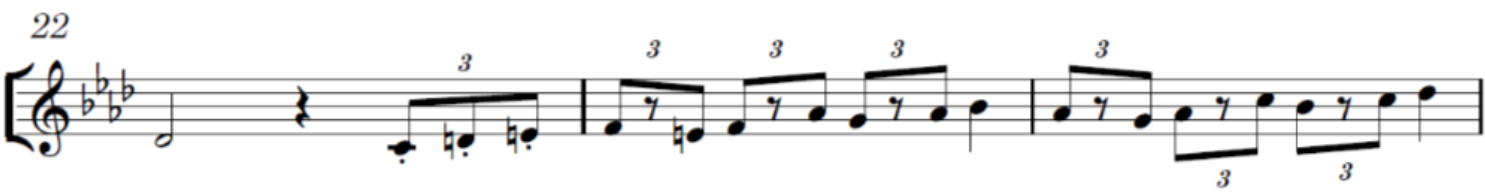

1. Tumbling...........

2. ..Tumbling.

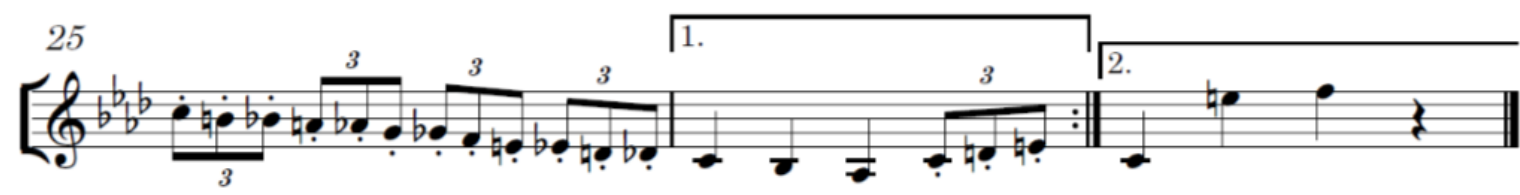

1.

1. Change the movement

2.

2. Jump-Finish

Skeletons that jumped left in the period jump in the opposite direction in the repetition of the period. As in the first part, the effect of finishing in the second volta of the third part is expressed by a movement from top to bottom. It is suggested to implement the same movements in the same parts in the first stage of the music teaching.

\section{Conclusion, discussion and suggestions}

Those who perform a piece, undertake the task of transforming the notes into a 'sensation'. The technical, aesthetic levels and even their sincerity in performing the vocalisation transform the piece into a 'concretisation stage'. What about the audience? The level of tendency to respond to and guide mental stimuli differs in every person; everyone bears different priorities, different aesthetic expectations and different perceptions. Therefore, listeners are rarely able to grasp the music offered to them, even partially. What if mental potential does not create a suitable position for a request to define and guide a corridor? If the expectations are different, how will 'understandability' become a shared common value? Or is the style key point? Not what it says, but how it is said? (Sünder, 1999).

Understanding what a piece says or how it is performed is about the musical education given in a systematic and orderly manner. Rather than being a 'result'-oriented lesson, music appears as an everlasting 'educational process' that a person will encounter throughout his/her life. For this reason, parents and teachers should try to ensure that the child establishes the relationship between 'music 
and life' and to increase the level of awareness of their children from the very beginning. The first and most important relationship between music and life is 'rhythm'.

The entire universe continues its existence through a constant rhythmic movement. There are other rhythms that depend on the main rhythms, such as the rotation of the Milky Way that we are in, the rotation of the earth around the sun: seasons, day and night, sleeping and waking, and even our heartbeats are the main rhythm. A heart whose rhythm is disturbed is accepted as diseased, and efforts are made to switch to a regular rhythm. For a balanced life, all our body rhythms should be orderly. In short, the balance required for the survival of the universe, nature and our own body essentially means the continuation of a rhythm. The main rhythm is not formed in a person who cannot set forward. For all these reasons, the development of the main rhythm, balance and sense of rhythm in the child is an issue that concerns not only the music lesson but also all areas (Morgül, 2001).

Therefore, one of the most important gains that should be given to children in music education should be 'rhythmic education'. It should be ensured that educational and instructive parts suitable for the age group are accompanied by movements (applause, stamping foot the ground etc.). It should also be enabled that these exercises are carried out through dance, and children who instinctively act in accordance with the unit beat or do not act should be well observed. New gains should be added to the dances that children naturally do through games. Dances performed by gamifying, such as soldier walking or robot walking, accompanied by music not only provide the child with fun, but also cause the child to develop a sense of unit beat without being aware of it. Thanks to rhythm training and rhythm development, the precondition for the child's new acquisitions in music education will be provided to a large extent.

'Movement' is also of great importance in teaching the basic concepts of the music because the information to be realised in kinaesthetic manner contains the cognitive process as well. The movements to be applied in line with the consciousness of the basic concepts related to music education will be the greatest evidence that the information is clearly understood and gives meaning.

In the process of teaching or reinforcing knowledge, it is necessary to use a variety of educational and instructive materials that engage children's attention and help them do what is requested enthusiastically. One of these materials is believed to be 'cartoons', which reserves an important place in children's lives. For this reason, the Silly Symphony series, which is considered to be a nourishing and supportive cartoon in terms of musical education, as well as being visually attractive, was chosen. The element that enables the Silly Symphony cartoon, a Walt Disney production that was shown between 1929 and 1939, to be used in music education is that the music in this cartoon was composed before the images. Because music is created before images, the image was drawn according to the technical and structural features of the music. Based on the notion that the cartoon, consisting of 75 episodes with the same logic, can be used as a supportive or instructive resource in music education, it is necessary to analyse the research subject and the first film of the series, The Skeleton Dance, in order to examine the relationship between the cartoon's music and movement.

As a result of examining the cartoon, The Skeleton Dance, it was determined that the sounds 'heard' in the cartoon were integrated with the 'visible' movements, and the movements were drawn according to the phrase or periods of the music consisting of a three-part song form. Despite having the same structure, different movements were made in the repeating of the first and third parts $(A)$ and the second part (B) with a volta. It is thought that the reason for the differentiation of movements drawn in accordance with the structure of phrases or periods is the need for diversification in terms of cartoon visuality. In the movements that will be recreated according to the age characteristics of the children, it 
is beneficial to make the same movement in all repetitions and to make the same movement in both the first and third compartments $(A)$ with the same melody, although a period is repeated with voltas in the first stage (B). As information is reinforced and transformed into permanent behaviours, it is recommended that the movements be diversified, as in the cartoon.

The situation, where the audible and the visible complement each other, is seen as a facilitator in the process of giving, teaching and reinforcing rhythm education. Counting the unit beat rhythmically from one to four regularly after determining the number of measures by feeling reveals the measures. In this way, it is easily understood which movements are made in which measures and which scene / motion / movement lasts for how many measures or how many beats, and thus both music and movements become understandable. Thus, it is understood why the repeated movements are repeated if correct and appropriate directions are made (form information).

The utilisation of didactic works-productions in which music and movement are so compatible in music education can reinforce the desired goal; cognitive lecturing can be supported by demonstrating appropriate examples. Having people of all age groups, especially younger children, watch scenes suitable for the subject/concept to be taught from cartoons, can accelerate the learning process and increase the permanence of the learned concepts.

Thanks to interpretation of the relationship between movement and music, the child can learn to concentrate his/her attention on a job and make a habit of 'listening'. The child can have the consciousness to understand the basic concepts of music and the structure of a piece (motif, question phrase, answer phrase, period) better as he/she sees, listens, understands, reinforces and applies them through correct and appropriate information practice. This awareness may help the child gain awareness and look at life from a different perspective.

Although it seems to be an old production compared to today's technology, it is believed that the cartoon is a production that can engage the attention of children in a short time, thanks to the supportive guidance of the family or teachers. The series, which can be easily accessed, thanks to YouTube, the social media platform considered to be the most preferred by individuals of all age groups, especially younger children, also has the characteristics of a beautiful music archive. Since seeing and applying movements in terms of form information will require listening to music more consciously, it is thought that the cartoon series Silly Symphony, especially The Skeleton Dance, will have a significant impact on the musical taste of children as well. Thanks to the Silly Symphony series, which embodies outstanding examples of western classical music and jazz music, as well as traditional and popular songs and rhymes, the child will encounter many different types of music and his/her musical taste will continue to improve. In this way, the child will be able to recognise the piece without any visuality.

In light of all these information and notions, the use of The Skeleton Dance, in which 'auditory' elements are perfectly complemented with 'visuals', is assessed positively in musical education. It is recommended that the educators make use of the Silly Symphony series as a 'main' or 'auxiliary' source in terms of drama and listening in the music lessons and examine the other cartoons of the series in order to determine their contribution to music education and also identify and examine similar productions. 
Angı, Ç. E. (2021). Examining the relation between form information and movement in music education: The skeleton dance. Cypriot Journal of Educational Science. 16 (2), 641-658. https://doi.org/10.18844/cjes.v16i2.5641

\section{References}

All the Tropes. (2020). The Skeleton Dance. https://allthetropes.org/wiki/The Skeleton Dance

Barrier, M. (2007). The Animated Man: A Life of Walt Disney. https://books.google.com.tr/books/about/The Animated Man.html?id=te1NcjZfRmIC\&redir esc=y

Can, A. (1995). Impacts of Cartoons on Children's Development and Communication in Television Programs for Preschool Children. (Unpublished doctoral dissertation). Marmara University, İstanbul. https://tez.yok.gov.tr/UlusalTezMerkezi/tezSorguSonucYeni.jsp

Cmrečak, J. (2018). Development of Animation in Disney's Short Films and How it Affected His First Two Featurelength Films. (Unpublished doctoral dissertation). Zadar University, Hrvatska. https://zir.nsk.hr/islandora/object/unizd:2232/datastream/PDF

Default Disney. The Skeleton Dance. https://hilaritybydefault.com/2016/12/06/default-disney-skeleton-dance$\underline{1929 /}$

Goldmark, D. \& Taylor, Y. (Ed.). (2002). The Cartoon Music Book. https://books.google.com.tr/books?id=5rfRdOMfTqsC\&hl=tr

Gordon, E. (2003). A Music Learning Theory for Newborn and Young Children. https://books.google.com.tr/books/about/A Music Learning Theory for Newborn and.html?id=UzJElh SraKsC\&redir esc=y

Hodeir, A. (2016). Genres and Forms in Music (4th ed.) (i. Usmanbaş, Trans.). Pan Publishing.

Inside the Magic. (2018). Walt Disney's Silly Symphonies: Year One-1929. https://insidethemagic.net/2018/01/walt-disneys-silly-symphonies-year-one-1929/

Inside the Magic. (2018). Silly Symphonies Cartoons part 10 - 1939 the final chapter. https://insidethemagic.net/2018/08/silly-symphony-cartoons-part-10-1939-the-final-chapter/

Károlyi, O. (2016). Introduction to Music (7th ed.) (M. Nemutlu, Trans.). Pan Publishing.

Kılıç, I. (2012). Music Education in Preschool (2nd ed.). Pegem Academy.

Kıral, B. (2020). Document Analysis as a Qualitative Data Analysis Method. Siirt University Journal of Social Sciences Institute Journal, 8 (15), 170-189. https://dergipark.org.tr/tr/download/article-file/1156348

Morgül, M. (2001). How to Teach Music. Yurtrenkleri Publishing House.

Oh, My Disney. (2016). The Serious History of Silly Symphonies. https://ohmy.disney.com/insider/2016/05/19/silly-symphonies/

Özevin, B., Bilen, S. (2015). Creative Dance. Music Education Publications.

Özmenteş, G. (2009). Body-mind relation in music. Music Culture and Music Education, In Proceedings of the International Congress of Asian and North African Studies, Volume II, 627-647. https://studylibtr.com/doc/742304/\%C3\%B6zmente\%C5\%9F--g\%C3\%B6kmen-m\%C3\%BCzi\%CC\%87ktebeden

Özkan, N. (2006). Rhythm Education and Modern Dance (2nd ed.). Nobel Publishing Distribution.

Shehan, K., P. (1987). Movement: The Heart of Music. Music Educators Journal, 74 (3), 24-30. https://doi.org/10.2307/3397937

Sığırtmaç, D., A. (2005). Music Education in Preschool Period. Kare Publications.

Sun, M., \& Seyrek, H. (1993). Music in Preschool Education. Mey Works Publications.

Sünder, K. (1999). On the Basic Problem with Music. Orchestra Journal, 304, 10-14. 
Angı, Ç. E. (2021). Examining the relation between form information and movement in music education: The skeleton dance. Cypriot Journal of Educational Science. 16 (2), 641-658. https://doi.org/10.18844/cjes.v16i2.5641

The Big Cartoon Database. Disney Silly Symphonies Animated Film Series. https://www.bcdb.com/cartoons/Walt Disney Studios/Shorts/Silly Symphonies/

The Disney Compendium. La Danza degli http://www.ilsollazzo.com/c/disney/scheda/TheSkeletonDance

TvTropes. Western Animation Symphonies. https://tvtropes.org/pmwiki/pmwiki.php/WesternAnimation/SillySymphonies

Watts, S. (1997). The Magic Kingdom: Walt Disney and the American Way of Life. https://books.google.com.tr/books/about/The Magic Kingdom.html?id=NgARIndAbjAC\&redir esc=y

Woods, G. D. (1987). Movement and General Music: Perfect Partners. Music Educators Journal, 74 (3), 35-42. https://doi.org/10.2307/3397939 